\title{
Caracterización ultrasonográfica de los órganos abdominales y pélvicos del oso de anteojos (Tremarctos ornatus) en cautiverio
}

\author{
Ultrasonographic characterization of of the abdominal and pelvic organs of the \\ spectacled bear (Tremarctos ornatus) in captivity
}

Camila Talavera C. ${ }^{1}$, Karina Muñoz D. ${ }^{2}$, Catalina Hermoza G. ${ }^{2}$, Ricardo Grandez R. ${ }^{1,3}$

\section{Resumen}

\begin{abstract}
El objetivo del presente estudio fue caracterizar las imágenes ultrasonográficas de los órganos abdominales y pélvicos del oso de anteojos (Tremarctos ornatus) en cautiverio. Se evaluaron ocho especímenes adultos ( 3 machos y 2 hembras) del zoológico Patronato del Parque de las Leyendas (Lima, Perú) y dos machos del Centro de Rescate Mundo Natural (Tingo María, Perú). Se utilizó un ecógrafo MyLab OneVet (Esaote) con transductor convexo 4-9 MHz. Se encontró que el riñón posee una forma multilobulada, similar al de otros úrsidos y al bovino doméstico. Las características ultrasonográficas y topográficas de los órganos abdominales, así como de los testículos son similares a las descritas en otras especies carnívoras domésticas, con variaciones proporcionales al mayor tamaño de la especie. El testículo presente un mediastinum testis poco remarcado y discontinuo.
\end{abstract}

Palabras clave: ultrasonografía, órganos abdominales, Tremarctos ornatus, Ursidae

\footnotetext{
${ }^{1}$ Sección de Biociencias y Ciencias Clínicas, Laboratorio de Vida Silvestre, Departamento Académico de Medicina Veterinaria y Zootecnia, Facultad de Medicina Veterinaria y Zootecnia, Universidad Peruana Cayetano Heredia, Lima, Perú

${ }^{2}$ Patronato del Parque de Las Leyendas - Felipe Benavides Barreda, Lima, Perú

${ }^{3}$ E-mail: rgrandez@hotmail.com
}

Recibido: 4 de abril de 2021

Aceptado para publicación: 18 de octubre de 2021

Publicado: 22 de diciembre de 2021

CLos autores. Este artículo es publicado por la Rev Inv Vet Perú de la Facultad de Medicina Veterinaria, Universidad Nacional Mayor de San Marcos. Este es un artículo de acceso abierto, distribuido bajo los términos de la licencia Creative Commons Atribución 4.0 Internacional (CC BY 4.0) [https:// creativecommons.org/licenses/by/4.0/deed.es] que permite el uso, distribución y reproducción en cualquier medio, siempre que la obra original sea debidamente citada de su fuente original 
The aim of this study was to characterize ultrasound images of the abdominal and pelvic organs of the spectacled bear (Tremarctos ornatus) in captivity. Eight adult specimens ( 3 males and 2 females) from the Patronato del Parque de las Leyendas zoo (Lima, Peru) and two males from the Mundo Natural Rescue Center (Tingo María, Peru) were evaluated. A MyLab OneVet (Esaote) ultrasound machine with a 4-9 MHz convex transducer was used. The kidney was found to have a multilobed shape, similar to that of other ursids and domestic bovines. The ultrasonographic and topographic characteristics of the abdominal organs, as well as of the testes, are similar to those described in other domestic carnivorous species, with variations proportional to the larger size of the species. The testis has a little marked and discontinuous mediastinum testis.

Key words: ultrasound, abdominal organs, Tremarctos ornatus, Ursidae

\section{INTRODUCCIÓN}

El oso de anteojos (Tremarctos ornatus) es un mamífero endémico de los Andes tropicales, perteneciente a la familia Ursidae, orden Carnívora. Es el único oso de Sudamérica, habita una variedad de ecosistemas como bosques y pasturas altiplánicas desde la sierra norte de Venezuela, Colombia, los Andes de Ecuador y Perú, hasta la zona este de Bolivia (Velez-Liendo y García-Rangel, 2017). Son animales omnívoros, basando su dieta principalmente en frutas y vegetación y ocasionalmente en carne. La especie cumple un rol importante como dispersor de semillas, permitiendo la sobrevivencia de una serie de plantas, como las Lauráceas (Gonzales et al., 2016).

MINAGRI-SERFOR es la entidad de gobierno que aprueba la clasificación y categorización de las especies amenazadas de fauna silvestre en el Perú y considera a $T$. ornatus en situación vulnerable mediante Decreto Supremo N. ${ }^{\circ}$ 004-2014-MINAGRI (MINAGRI-SERFOR, 2016). Esto implica que está prohibida su caza, captura, tenencia, transporte o exportación con fines comerciales. Además, se encuentra en la misma categoría en la Lista Roja de la Unión Internacional para la Conservación de la
Naturaleza (IUCN) (Velez-Liendo y GarcíaRangel, 2017) y en el Apéndice I de la Convención sobre el Comercio Internacional de Especies Amenazadas de Fauna y Flora Silvestres (CITES, 2017). Entre sus principales amenazas están la cacería y la pérdida de hábitat. Estos animales son cazados por razones de subsistencia, protección frente a los ataques hacia el ganado o cultivos, miedo al animal por razones culturales, y tráfico de individuos vivos o de partes de estos. Por otro lado, la fragmentación y pérdida de hábitat se da principalmente por la deforestación, crecimiento poblacional humano, explotaciones petroleras y mineras (Velez-Liendo y García-Rangel, 2017).

Perú y Bolivia han elaborado planes para su conservación (Wallace et al., 2014), así como en Venezuela que se formuló el «Plan de Acción para la Conservación del Oso Andino (T. ornatus) (2006-2016)» (Yerena et al., 2007). En 2016, Perú a través del MINAGRI-SERFOR se publicó el «Plan Nacional de Conservación del Oso Andino (T. ornatus) para el periodo 2016-2026», donde se identifica la situación actual de la especie y se menciona la existencia de una población en cautiverio. Además, menciona la falta de conocimiento sobre aspectos fisiológicos y reproductivos y el estado sanitario de la especie. Por esta razón, uno de sus ob- 
jetivos es realizar investigaciones in situ y ex situ sobre estos aspectos para la toma de decisiones orientadas a la conservación de la especie y su hábitat.

Existen diversas herramientas y pruebas para la evaluación física y fisiológica de animales en cautiverio que varían en niveles de riesgo e invasividad, como son los exámenes de patología clínica de sangre y orina, o aquellos basados en imágenes como radiografías y ultrasonografías. La ultrasonografía o ecografía es una herramienta que permite diferenciar entre una gama de tejidos (Barr et al., 2006), pudiéndose diferenciar estructuras normales de anormales para identificar patologías. Al tratarse de una prueba no invasiva, en tiempo real, cuyo equipo puede ser transportable a campo, permite su aplicación en el diagnóstico de diversas patologías en animales silvestres (Fowler y Miller, 2015). Un examen ecográfico general usualmente incluye los órganos abdominales y pélvicos (Matton y Nyland, 2016).

Dentro de las principales enfermedades reportadas en úrsidos en cautiverio se encuentran las patologías tegumentarias, gastrointestinales y oculares. Entre las gastrointestinales se encuentran las neoplasias, vólvulos, obstrucciones y la enfermedad inflamatoria intestinal, entre otras. Muchas de estas se pueden diagnosticar a través de la ecografía y con apoyo de exámenes complementarios (Fowler y Miller, 2015)

La literatura veterinaria referente a reportes ecográficos detallados en fauna silvestre es aún limitada, existiendo escasa información publicada acerca de la anatomía del oso de anteojos. Ante esto, el objetivo del estudio fue realizar la descripción ultrasonográfica de los órganos abdominales y pélvicos del oso de anteojos (T. ornatus) en cautiverio, información que será útil para reconocer las características normales de los órganos de ubicación abdominal y pélvica en esta especie, constituyendo una herramienta diagnóstica útil en el control sanitario rutinario en los ejemplares en cautiverio.

\section{Materiales y MéTodos}

El estudio comprendió la evaluación de ocho ejemplares adultos (Tremarctos ornatus). Seis de ellos (3 machos y 3 hembras) correspondieron a la colección del zoológico del Patronato del Parque de las Leyendas «Felipe Benavides Barreda», ubicado en Lima, Perú, y dos individuos machos de la colección del Centro de Rescate Mundo Natural ubicado en Tingo María, Perú. Los criterios de inclusión contemplaron ejemplares aparentemente sanos sin distinción de sexo o edad, sin historia de enfermedad en los últimos seis meses estando en cautiverio.

Los animales fueron anestesiados como parte de su control sanitario anual empleando dardos disparados con cerbatanas. Se utilizó $5-8 \mathrm{mg} / \mathrm{kg}$ ketamina y $1-1.5 \mathrm{mg} / \mathrm{kg}$ xilacina administrado vía intramuscular (Fowler y Miller, 2015), según los pesos de registros previos. Una vez bajo sedación, se procedió a realizar el examen físico completo rutinario y la toma de muestras de sangre periférica para los análisis de patología clínica correspondientes.

El procedimiento de evaluación ultrasonográfica se realizó con un equipo MyLab One Vet (Esaote, Italia) con transductor convexo SC3123, 9-4 MHz, ángulo 93․ Para una mejor visión de los órganos se aplicó etanol $70 \%$ para facilitar la aplicación de abundante gel de ultrasonido sobre la superficie de la piel y lograr un adecuado contacto del transductor con la superficie corporal.

Para describir la topografía de los órganos abdominales y pélvicos, la superficie abdominal se delimitó en nueve regiones por planos imaginarios (Evans y deLahunta, 1991) (Figura 1). Las regiones abdominales formadas por planos transversos se dividen en abdominal: craneal, media y caudal. Estas a su vez se dividen en tres, dando nueve regiones abdominales formadas por planos parasagitales (Done et al., 2010). El abdomen craneal inicia a la altura del apéndice xifoides, 

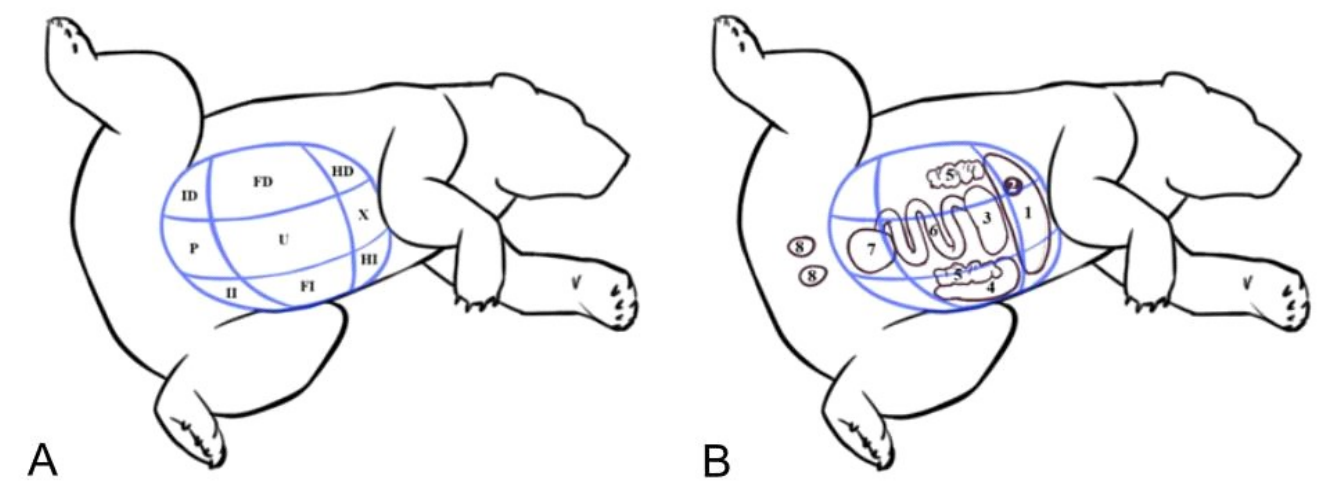

Figura 1. Regionalización anatómica y órganos abdominales del oso de anteojos (Tremarctos ornatus), adaptado de Evans y deLahunta (1991). (A) Regiones: HD (Hipocondrio derecho), HI (Hipocondrio izquierdo), X (Xifoidea), FD (Flanco derecho), FI (Flanco izquierdo), U (Umbilical), ID (Inguinal derecho), II (Inguinal izquierdo), P (Púbica). (B) órganos: 1 (Hígado), 2 (Vesícula biliar), 3 (Estómago), 4 (Bazo), 5 (Riñones), 6 (Intestino), 7 (Vejiga), 8 (Testículos)

extendiéndose hasta la altura de los arcos costales, creando la región xifoidea en lo ventral y a lo lateral el hipocondrio derecho e izquierdo. El abdomen medio inicia caudal a la línea imaginaria que limita el abdomen craneal, y termina en una línea imaginaria entre las dos crestas ilíacas. A su vez, este abdomen medio se divide en la región umbilical en la zona ventral y el flanco derecho e izquierdo a lo lateral. Finalmente, el abdomen caudal inicia desde la línea intertubercular y va hasta el final del abdomen; la zona ventral es la región púbica y los laterales la región inguinal (adaptado de Evans y deLahunta, 1991).

El examen ecográfico se inició con la visualización del hígado y vesícula biliar en el abdomen craneal, luego se evaluaron ambos riñones y el bazo en los respectivos flancos, se prosiguió con el estómago en el abdomen medio y finalmente en la región pélvica y escrotal se evaluó la vejiga y órganos reproductivos. Durante la evaluación ultrasonográfica se registraron las características de topografía, morfología, ecogenicidad, ecotextura, arquitectura y dimensiones de los órganos de ubicación abdominal y pélvica. Asimismo, se hizo el registro digital de imágenes $\mathrm{y}$ videos del procedimiento. Estos datos fueron sometidos a estadística descriptiva obteniéndose la media como medida de tendencia central, la desviación estándar y rango como medidas de dispersión. Los datos se presentan en cuadros.

Al haber limitada información sobre los parámetros ecográficos de ejemplares sanos en esta especie, los datos registrados en la evaluación ecográfica de los órganos abdominales y pélvicos fueron comparados con aquellas del único estudio ecográfico realizado post mortem de un oso de anteojos hembra por Cahua y Sato (2012). Adicionalmente, se emplearon referencias de hallazgos de estudios similares de otras especies de la familia Ursidae y Bovidae, y en otras especies de carnívoros, como el perro doméstico (Canis lupus familiaris). 
Cuadro 1. Estadísticos de edad, peso, sexo y dimensiones de los órganos abdominales, obtenidos mediante ultrasonografía en ocho ejemplares de Tremarctos ornatus en cautiverio

\begin{tabular}{|c|c|c|c|c|c|c|c|c|c|c|}
\hline \multirow{2}{*}{ Espécimen } & \multirow{2}{*}{ Estadístico } & \multirow{2}{*}{$\begin{array}{l}\text { Edad } \\
\text { (años) }\end{array}$} & \multirow{2}{*}{$\begin{array}{r}\text { Peso } \\
\text { (kg) }\end{array}$} & \multirow{2}{*}{$\begin{array}{c}\text { Bazo } \\
\begin{array}{c}\text { Espesor } \\
(\mathrm{cm})\end{array}\end{array}$} & \multicolumn{2}{|c|}{$\begin{array}{c}\text { Riñón } \\
\text { derecho }\end{array}$} & \multicolumn{2}{|c|}{$\begin{array}{c}\text { Riñón } \\
\text { izquierdo }\end{array}$} & \multirow{2}{*}{$\begin{array}{c}\text { Estómago } \\
\text { Espesor } \\
\text { de pared } \\
(\mathrm{cm})\end{array}$} & \multirow{2}{*}{$\begin{array}{c}\mathrm{V} . \\
\text { biliar } \\
\begin{array}{c}\text { Largo } \\
(\mathrm{cm})\end{array}\end{array}$} \\
\hline & & & & & $\begin{array}{c}\text { Largo } \\
(\mathrm{cm})\end{array}$ & $\begin{array}{c}\text { Ancho } \\
(\mathrm{cm})\end{array}$ & $\begin{array}{l}\text { Largo } \\
(\mathrm{cm})\end{array}$ & $\begin{array}{l}\text { Ancho } \\
(\mathrm{cm})\end{array}$ & & \\
\hline \multirow{4}{*}{$\begin{array}{l}\text { Machos } \\
(\mathrm{n}=5)\end{array}$} & Promedio & 19.2 & 129.8 & 3.50 & 7.45 & 3.21 & 7.88 & 3.50 & 1.34 & 5.82 \\
\hline & $\mathrm{DS}$ & 7.7 & 16.9 & 0.48 & 2.27 & 0.73 & 2.41 & 0.67 & 0.30 & 1.34 \\
\hline & Máximo & 27 & 140 & 4.04 & 9.5 & 4.35 & 9.66 & 4.11 & 1.57 & 7.37 \\
\hline & Mínimo & 10 & 100 & 2.97 & 3.65 & 2.43 & 3.69 & 2.43 & 0.93 & 4.30 \\
\hline \multirow{4}{*}{$\begin{array}{l}\text { Hembras } \\
(\mathrm{n}=3)\end{array}$} & Promedio & 19.7 & 109.3 & 3.00 & 6.86 & 3.05 & 7.48 & 2.64 & 1.18 & 4.62 \\
\hline & $\mathrm{DS}$ & 3.8 & 27.8 & 0.78 & 1.79 & 0.34 & 0.97 & 0.20 & 0.33 & 0.53 \\
\hline & Máximo & 24 & 141 & 3.90 & 8.64 & 3.36 & 8.41 & 2.85 & 1.51 & 5.14 \\
\hline & Mínimo & 17 & 89 & 2.52 & 5.06 & 2.69 & 6.48 & 2.45 & 0.86 & 4.09 \\
\hline \multirow{4}{*}{$\begin{array}{l}\text { Total } \\
(\mathrm{n}=8)\end{array}$} & Promedio & 19.4 & 122.1 & 3.31 & 7.23 & 3.15 & 7.73 & 3.18 & 1.27 & 5.37 \\
\hline & $\mathrm{DS}$ & 6.1 & 22.3 & 0.61 & 1.99 & 0.59 & 1.91 & 0.69 & 0.30 & 1.22 \\
\hline & Máximo & 27 & 141 & 4.04 & 9.5 & 4.35 & 9.03 & 4.04 & 1.57 & 7.37 \\
\hline & Mínimo & 10 & 89 & 2.52 & 3.65 & 2.43 & 3.69 & 2.43 & 0.86 & 4.09 \\
\hline
\end{tabular}

\section{Resultados}

El manejo y protocolo de anestesia utilizados permitieron realizar el procedimiento ecográfico y el control sanitario en general sin inconveniente. Los animales no presentaron efecto adverso alguno durante el procedimiento anestésico ni en el tiempo de recuperación posterior a la anestesia. Los estadísticos de las edades y pesos de los especímenes evaluados se presentan en los cuadros 1 y 2 ; llamando la atención una hembra obesa $(141 \mathrm{~kg})$ que superó en más de 40 $\mathrm{kg}$ el peso de sus congéneres.

Los resultados del examen de patología clínica indicaron valores dentro de los parámetros normales, con excepción de la hembra obesa que presentó niveles elevados para glucosa $(112 \mathrm{mg} / \mathrm{dl})$ y colesterol (461 $\mathrm{mg} / \mathrm{dl}$ ), aunque dentro los rangos referenciales, según los registros de Species360 para T. ornatus (Fowler y Miller, 2015). Sin embargo, el nivel elevado de triglicéridos (1030 $\mathrm{mg} / \mathrm{dl}$ ) sobrepasó los valores referenciales (87.93-196.04 mg/dl) (Castellanos et al., 2010). No obstante, este ejemplar fue incluida en el estudio al no presentar alteraciones al examen clínico.

Las características ecográficas: topografía, márgenes, forma, ecotextura y ecogenicidad del bazo, hígado, vesícula biliar, riñones, estómago, vejiga en el abdomen (Cuadro 1); y en el caso de los machos, los testículos en las bolsas escrotales se encuentran descritas en el Cuadro 3. Las dimensiones de los órganos abdominales se detallan en el Cuadro 2 y de los órganos los pélvicos en el Cuadro 3. 
Cuadro 2. Estadísticos de edad, peso, sexo y dimensiones de los órganos pélvicos, obtenidos mediante ultrasonografía en ocho ejemplares de Tremarctos ornatus en cautiverio

\begin{tabular}{|c|c|c|c|c|c|c|c|c|}
\hline \multirow{3}{*}{ Especímenes } & \multirow{3}{*}{ Estadístico } & \multirow{2}{*}{\multicolumn{2}{|c|}{$\begin{array}{c}\text { Datos } \\
\text { demográficos }\end{array}$}} & \multirow{3}{*}{$\begin{array}{c}\text { Vejiga } \\
\text { Grosor de } \\
\text { pared }(\mathrm{cm})\end{array}$} & \multicolumn{4}{|c|}{ Testículos } \\
\hline & & & & & \multicolumn{2}{|c|}{ Derecho } & \multicolumn{2}{|c|}{ Izquierdo } \\
\hline & & $\begin{array}{l}\text { Edad } \\
\text { (años) }\end{array}$ & $\begin{array}{l}\text { Peso } \\
\text { (kg) }\end{array}$ & & $\begin{array}{l}\text { Largo } \\
(\mathrm{cm})\end{array}$ & $\begin{array}{l}\text { Ancho } \\
(\mathrm{cm})\end{array}$ & $\begin{array}{l}\text { Largo } \\
(\mathrm{cm})\end{array}$ & $\begin{array}{l}\text { Ancho } \\
(\mathrm{cm})\end{array}$ \\
\hline \multirow[t]{4}{*}{ Machos $(n=5)$} & Promedio & 19.2 & 129.8 & 0.67 & 3.96 & 2.53 & 4.29 & 2.49 \\
\hline & DS & 7.7 & 16.9 & 0.40 & 2.02 & 0.60 & 2.84 & 0.58 \\
\hline & Máximo & 27 & 140 & 1.10 & 7.51 & 3.36 & 9.35 & 3.23 \\
\hline & Mínimo & 10 & 100 & 0.23 & 2.55 & 1.82 & 2.60 & 1.84 \\
\hline \multirow{4}{*}{$\begin{array}{l}\text { Hembras } \\
(n=3)\end{array}$} & Promedio & 19.7 & 109.3 & 0.51 & - & - & - & - \\
\hline & DS & 3.8 & 27.8 & 0.09 & - & - & - & - \\
\hline & Máximo & 24 & 141 & 0.61 & - & - & - & - \\
\hline & Mínimo & 17 & 89 & 0.45 & - & - & - & - \\
\hline \multirow[t]{4}{*}{ Total $(n=8)$} & Promedio & 19.4 & 122.1 & 0.61 & 3.19 & 2.55 & 3.16 & 2.44 \\
\hline & $\mathrm{DS}$ & 6.1 & 22.3 & 0.32 & 0.47 & 0.61 & 0.42 & 0.57 \\
\hline & Máximo & 27 & 141 & 1.10 & 3.65 & 3.36 & 3.69 & 3.23 \\
\hline & Mínimo & 10 & 89 & 0.23 & 2.55 & 1.82 & 2.6 & 1.84 \\
\hline
\end{tabular}

El hígado se encontró en la región craneal del abdomen, la región xifoidea, el hipocondrio izquierdo y parte del hipocondrio derecho. Está delimitado cranealmente por el diafragma y caudalmente por el estómago. Presentó bordes continuos y un parénquima de ecotextura y ecogenicidad media y homogénea. La vascularización hepática se observó como tractos anecoicos característicos de este órgano (Figura 2A).

La vesícula biliar se observó piriforme, ubicándose en el límite de la región xifoidea y del hipocondrio derecho, rodeada por parénquima hepático. El margen interno se observó continuo e hiperecogénico, de grosor variable según el volumen contenido. Cuatro individuos presentaron la pared vesicular discretamente gruesa e hiperecogénica; en el resto, la pared fue delgada. El contenido se observó anecoico, sin evidencia de sedimento biliar (Figura 2A).
El bazo se ubicó en la región del flanco izquierdo, craneal al riñón izquierdo. Los márgenes fueron lisos, presentando una cápsula delgada continua hiperecogénica. En cuanto a la forma, se reconoció una cabeza prominente con un pliegue conjuntivo que la delimitaba del cuerpo. El bazo presentó un parénquima homogéneo, de ecogenicidad y ecotextura granular fina y densa. pudiendo observar en el parénquima esplénico estructuras vasculares y venas esplénicas (Figura 2B).

El estómago se localizó en la región del abdomen medio, entre la región xifoidea y umbilical, abarcando también parte de los flancos. Presentó una forma sacular e irregular, variando en cada individuo según el contenido de gas o alimento. El órgano mostró la pared gástrica con capas de ecogenicidad alternada y pliegues cortos; observándose la mucosa delgada e hipoecogénica, la submucosa de grosor moderado e hiperecogénica, 
Cuadro 3. Características ultrasonográficas (topografía, márgenes, forma, ecotextura y ecogenicidad) de los órganos abdominales y pélvicos en ocho ejemplares de Tremarctos ornatus en cautiverio

\begin{tabular}{|c|c|c|c|c|c|c|c|}
\hline Órgano & Estómago & $\begin{array}{c}\text { Vesícula } \\
\text { biliar }\end{array}$ & Bazo & Hígado & Riñones & Vejiga & Testículos \\
\hline Topografía & $\begin{array}{c}\text { Región } \\
\text { xifoidea y } \\
\text { umbilical. } \\
\text { Abarca } \\
\text { parte de los } \\
\text { flancos }\end{array}$ & $\begin{array}{l}\text { Límite de la } \\
\text { región } \\
\text { xifoidea e } \\
\text { hipogastrio } \\
\text { derecho. } \\
\text { Rodeada } \\
\text { por } \\
\text { parénquima } \\
\text { hepático }\end{array}$ & $\begin{array}{l}\text { Flanco } \\
\text { izquierdo }\end{array}$ & $\begin{array}{l}\text { Parte del } \\
\text { hipocondrio } \\
\text { derecho, } \\
\text { región } \\
\text { xifoidea e } \\
\text { hipocondrio } \\
\text { izquierdo }\end{array}$ & $\begin{array}{c}\text { Región } \\
\text { craneal de los } \\
\text { flancos. } \\
\text { Derecho más } \\
\text { craneal que } \\
\text { izquierdo }\end{array}$ & Pelvis & $\begin{array}{c}\text { En bolsas } \\
\text { escrotales } \\
\text { ubicadas en } \\
\text { región } \\
\text { perineal / } \\
\text { pélvica }\end{array}$ \\
\hline Márgenes & Continuos & $\begin{array}{c}\text { Bordes } \\
\text { continuos e } \\
\text { hiperecogén } \\
\text { ico }\end{array}$ & $\begin{array}{c}\text { Lisos y } \\
\text { cápsula } \\
\text { delgada } \\
\text { hiperecogéni } \\
\text { ca continua }\end{array}$ & Continuos & $\begin{array}{l}\text { Cápsula de } \\
\text { bordes } \\
\text { continuos } \\
\text { definida y } \\
\text { ecogénica }\end{array}$ & $\begin{array}{c}\text { Margen } \\
\text { interno } \\
\text { continuo } \\
\text { ligeramente } \\
\text { ondulante }\end{array}$ & $\begin{array}{c}\text { Regulares } \\
\text { hiperecoicos } \\
\text { con } m \text {. testis } \\
\text { discontinuo }\end{array}$ \\
\hline Forma & $\begin{array}{l}\text { Sacular e } \\
\text { irregular, } \\
\text { varía según } \\
\text { contenido }\end{array}$ & Piriforme & $\begin{array}{c}\text { Cabeza } \\
\text { prominente } \\
\text { con pliegue } \\
\text { conjuntivo } \\
\text { que la } \\
\text { delimita }\end{array}$ & $\begin{array}{c}\text { Estructura } \\
\text { parenquima- } \\
\text { tosa sólida }\end{array}$ & $\begin{array}{l}\text { Multilobu- } \\
\text { lados con } \\
\text { médula } \\
\text { estrecha }\end{array}$ & $\begin{array}{l}\text { Redondeada. } \\
\text { Varía según } \\
\text { contenido }\end{array}$ & Ovoide \\
\hline $\begin{array}{c}\text { Ecogenici- } \\
\text { dad / } \\
\text { Ecotextura/ } \\
\text { Contenido }\end{array}$ & $\begin{array}{c}\text { Mucosa } \\
\text { delgada } \\
\text { hipo } \\
\text { ecogénica } \\
\text { con } \\
\text { pliegues } \\
\text { cortos. } \\
\text { Contenido } \\
\text { variable }\end{array}$ & $\begin{array}{l}\text { Contenido } \\
\text { anecoico }\end{array}$ & $\begin{array}{l}\text { Parénquima } \\
\text { homogéneo } \\
\text { granular fino }\end{array}$ & $\begin{array}{c}\text { Ecotextura } \\
\text { granular } \\
\text { media } \\
\text { homogénea } \\
\text { con tractos } \\
\text { anecoicos, } \\
\text { vasos } \\
\text { sanguíneos }\end{array}$ & $\begin{array}{c}\text { Corteza de } \\
\text { ecogenicidad } \\
\text { y ecotextura } \\
\text { granular } \\
\text { media } \\
\text { homogénea. } \\
\text { La corteza } \\
\text { forma } \\
\text { estructuras de } \\
\text { aspecto } \\
\text { nodular }\end{array}$ & $\begin{array}{c}\text { Capas poco } \\
\text { definidas, de } \\
\text { grosor } \\
\text { variable } \\
\text { dependiendo } \\
\text { de } \\
\text { contenido, } \\
\text { anecoico }\end{array}$ & $\begin{array}{l}\text { Parénquima } \\
\text { granular } \\
\text { medio } \\
\text { homogéneo }\end{array}$ \\
\hline
\end{tabular}

una muscular gruesa e hipoecogénica, y una serosa fina e hiperecogénica (Figura 3A).

Los riñones, se encontraron en la región del flanco derecho e izquierdo, respectivamente; siendo el derecho más craneal que el izquierdo. Tuvieron forma multilobulada, de modo que estos lóbulos se dividen también en corteza y médula, presentando entre 10 a 12 lóbulos por riñón. Los bordes del riñón fueron hiperecogénicos, mientras que la corteza fue de ecogenicidad y ecotextura granular media homogénea, en tanto que la médula correspondió en cada lóbulo a una pequeña área central irregular anecoica (Figura 3B).

En la región pélvica se encontró la vejiga. Su forma fue redondeada y el tamaño varió según la cantidad de orina. Presentó bordes regulares, con las capas de la pared poco definidas, un margen interno continuo ligeramente ondulante y un contenido 


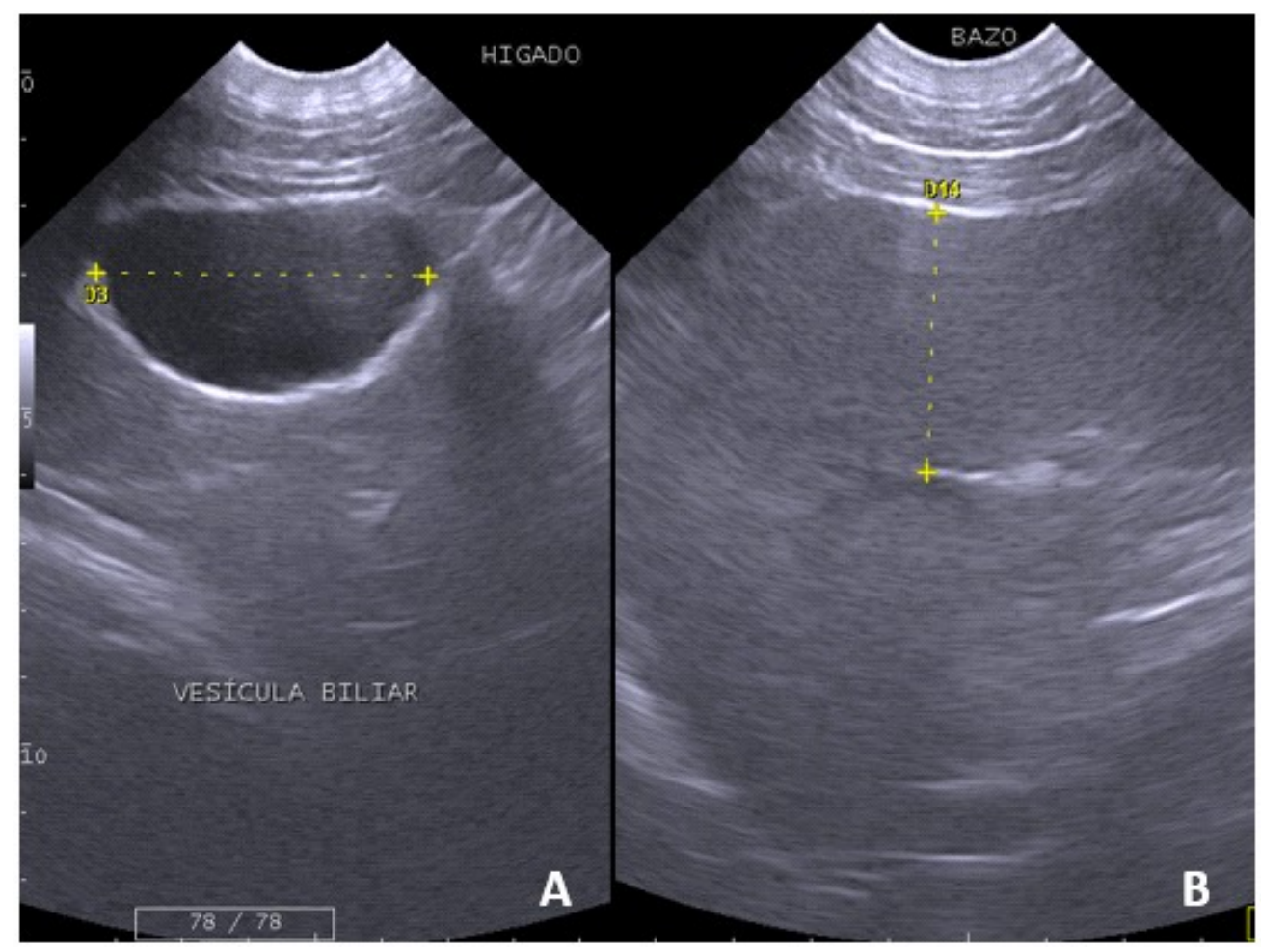

Figura 2. Imágenes ultrasonográficas del hígado, vesícula biliar y bazo del oso de anteojos (Tremarctos ornatus). (A) Hígado, se observa un parénquima hepático normal de ecotextura granular media homogénea. Vesícula biliar con contenido anecoico y pared hiperecogénica $(5.0 \mathrm{~cm}$ de longitud) rodeada por parénquima hepático de ecotextura

anecoico (Figura 4A). Los testículos son ovoides y se ubican en la parte externa de la región pélvica, en las bolsas escrotales. Poseen márgenes regulares continuos e hiperecoicos y un parénquima granular medio homogéneo. El mediastinum testis se observó como una tenue línea hiperecogénica y discontinuo al corte sagital (Figura 4B). Para el caso de las hembras, no se pudo distinguir las secciones del aparato reproductor.

\section{Discusión}

El manejo y protocolo de sedación empleados permitió realizar el control sanitario y procedimiento ecográfico sin dificultad. Siendo los resultados del examen de patología clínica normales (con la excepción de un individuo), se esperaría que los osos no presentasen alteraciones anatomopatológicas en los órganos, como se corroboró en los resultados. Los resultados fueron comparados principalmente con un reporte realizado en una osa de anteojos en el post portem. Ese animal de 28 años y de $38 \mathrm{~kg}$ de peso fue criado en cautiverio, y eutanasiado debido a un cuadro de inanición y emaciación crónica (Cahua y Sato, 2012).

El hígado se visualizó abarcando parte del hipocondrio derecho, región xifoidea e hipocondrio izquierdo, mientras que Cahua y Sato (2012) lo describieron en los espacios derecho e izquierdo del abdomen, pero en ambos casos limitado por el arco costal, al igual que en el perro (Penninck y D'Anjou, 2008). Esta diferencia podría deberse al fun- 

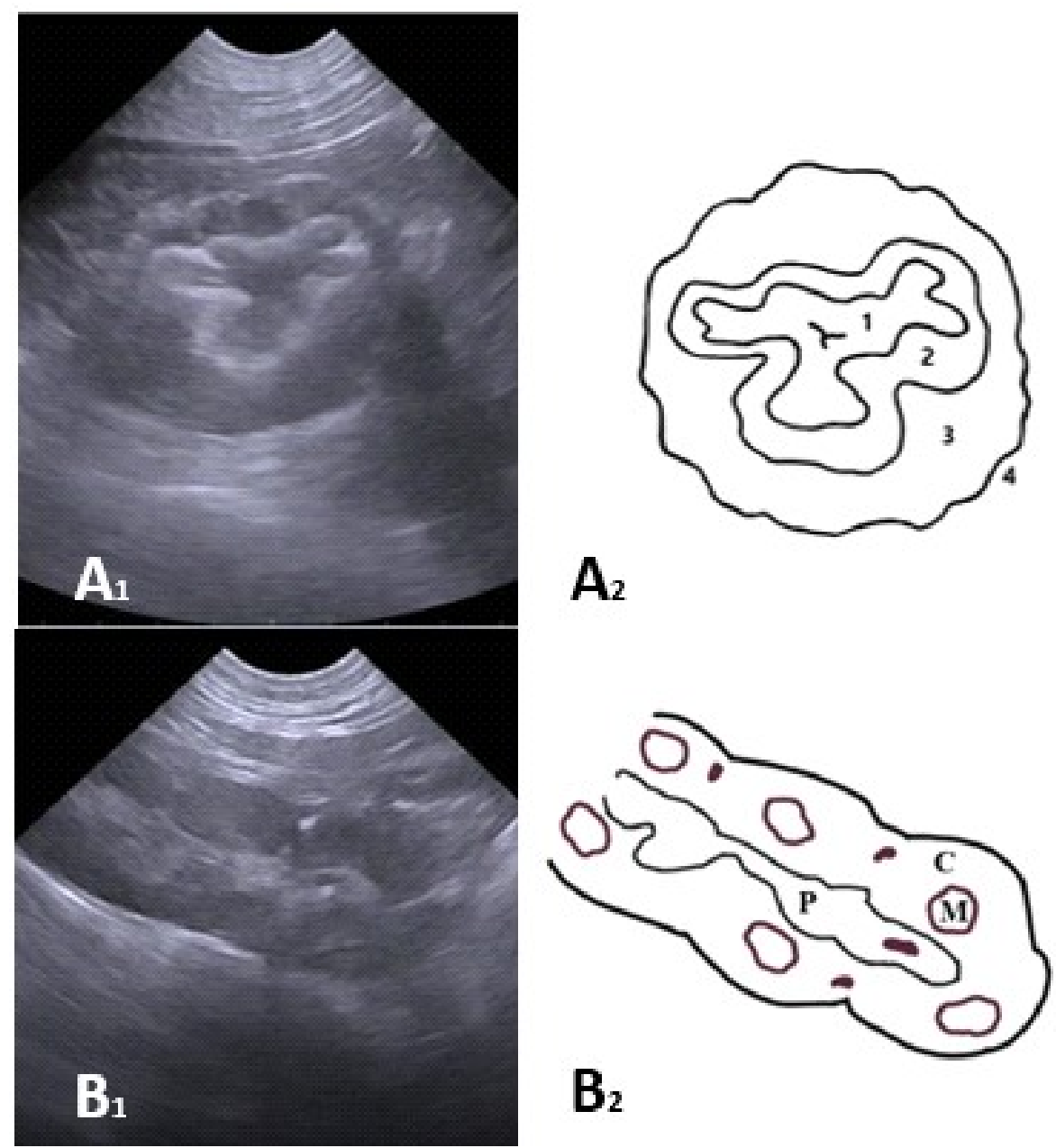

Figura 3. Imágenes ultrasonográficas del estómago y riñón del oso de anteojos (Tremarctos ornatus) (A1) Corte transversal del estómago sin contenido. Se diferencian las cuatro capas de la pared del estómago; y en el dibujo (A2) se esquematizan la mucosa (1), submucosa (2), muscular (3), serosa (4). (B1) Corte longitudinal del riñón. Se aprecian los lóbulos con buena diferenciación cortico medular; y la pelvis; (B2) ilustrados en el dibujo: P (Pelvis), M (Médula), C (Corteza)

damento que usaron Cahua y Sato (2012) para delimitar las áreas del abdomen, información que no especifican en su reporte. En la necropsia describieron seis lóbulos: lateral derecho, medial derecho, cuadrado, medial izquierdo, lateral izquierdo y caudado; tal como lo describe Raven (1936) en el oso panda (Ailuropoda melanoleuca). Sin embargo, en este estudio, como sucede en el perro y otras especies domésticas, a pesar de que el hígado se divide en lóbulos, estos no se logran diferenciar ecográficamente (Matton y Nyland, 2016).
Cahua y Sato (2012) describen el parénquima hepático como homogéneo, lo cual concuerda con lo hallado en el presente estudio; sin embargo, ellos encontraron el hígado moderadamente hipoecogénico y de grano fino, mientras que en el presente estudio se observó un parénquima de textura granular media, al igual que lo descrito en el perro (Matton y Nyland, 2016). Al compararlo con el bazo, el hígado es ligeramente hipoecoico y de ecotextura más granular, situación semejante a lo descrito en el perro (Penninck y D'Anjou, 2008). Los tractos anecoicos ob- 


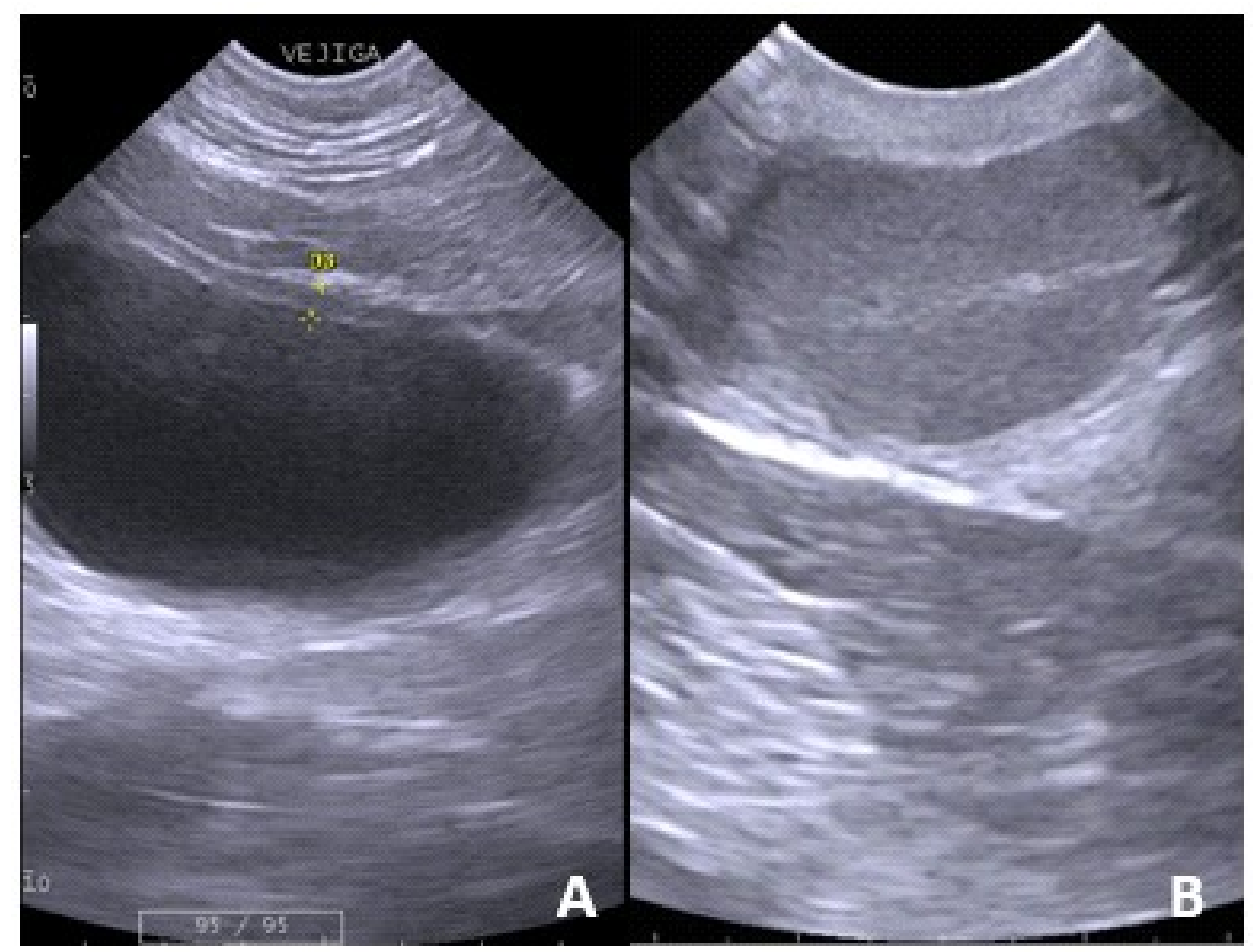

Figura 4. Imágenes ultrasonográficas de vejiga y testículo del oso de anteojos (Tremarctos ornatus) (A) La vejiga se observa con las capas de la pared poco definidas y un contenido anecoico, pared de $0.47 \mathrm{~cm}$ de espesor. (B) Testículo observándose el mediastinum tesis, hiperecogénico y discontinuo.

servados correspondientes a vasos sanguíneos también han sido descritos en el perro y otras especies domésticas como ramas de las venas hepáticas y portales (Matton y Nyland, 2016).

Los animales que presentan obesidad pueden tener el hígado con ciertas alteraciones ecográficas como aumento de la ecogenicidad y aumento del tamaño, aunque hay casos donde no se encuentran cambios específicos en la ecogenicidad (Matton y Nyland, 2016). En el caso de la hembra obesa el parénquima hepático fue similar al del resto de los animales en estudio.
La vesícula biliar se ubicó rodeada de parénquima hepático, de aspecto piriforme, al igual que lo presenta el perro (Penninck y D'Anjou, 2008). Es de bordes continuos hiperecogénicos y contenido anecoico, lo que coincide con la descripción de Cahua y Sato (2012), quienes reportaron la vesícula biliar con un largo de $7.69 \mathrm{~cm}$, valor que está dentro del rango de los valores del presente estudio.

Las secciones del sistema gastrointestinal tales como estómago y asas intestinales coincidieron con lo característico de los carnívoros, lo que concuerda con la descrip- 
ción hecha en los úrsidos (Cubas et al., 2014; Fowler y Miller, 2015). A pesar de ser animales con dieta omnívora, casi herbívora (Chávez, 2018), poseen un sistema gastrointestinal simple y no poseen ciego, características similares a la descrita en el oso panda, especie estrictamente herbívora (Langer, 2017). El estómago al igual que en el estudio de Cahua y Sato (2012) se presentó en la región xifoidea y umbilical, abarcando parte de los flancos, aunque aquel estudio menciona que solamente se extiende medialmente hasta el riñón derecho.

A nivel de la pared del estómago se identificaron ecográficamente las siguientes capas: una mucosa delgada hipoecogénica, una submucosa moderada hiperecogénica, una capa muscular hipoecogénica gruesa y una serosa hiperecogénica. Cahua y Sato (2012) también describieron una capa muscular bastante gruesa, hipoecogénica y de grano grueso, solamente descrita a nivel de la porción descendente del estómago. La pared del estómago en los osos de anteojos fue mucho más gruesa que la descrita para perros, 0.30 a $0.50 \mathrm{~cm}$ (Matton y Nyland, 2016). Sin embargo, es importante recalcar que en las evaluaciones del grosor de la pared debe considerarse el contenido y distensión del estómago al momento de la evaluación (Penninck y D'Anjou, 2008).

El riñón izquierdo y derecho se ubicaron en la parte craneal del flanco izquierdo y derecho, respectivamente, siendo el derecho más craneal que el izquierdo, igual a lo descrito en el perro (Matton y Nyland, 2016). Presentaron una morfología multilobulada, como lo describe Cahua y Sato (2012), semejante a la descrita en el bovino doméstico, Bos taurus (Carvalho et al. 2009), en el oso polar, Ursus maritimus (Bechshøft et al., 2011) y en el oso pardo, Ursus arctos (Goœcicka y Tomasik. 1979); quienes indican que estos lóbulos funcionan de forma independiente y se dividen en corteza y médula. En el bovino, el riñón posee un aproximado de 20 lóbulos (Carvalho et al., 2009), mien- tras que Bechshøft et al. (2011) reportó un riñón de oso polar con 47 lóbulos. En el presente estudio fue de aproximadamente de 10 a 12 lóbulos, probablemente debido al menor tamaño del oso de anteojos.

La explicación más probable para la forma lobulada de los riñones en los osos, al igual que las otras especies mencionadas, la proponen Stenvinkel et al. (2018), quienes postulan que es debido a las características de los túbulos contorneados proximales, que son de menor tamaño en comparación al resto de especies, por lo que tienen una menor capacidad para el flujo intraluminal, y al ser una especie de gran tamaño y tener la limitante de la longitud de estos túbulos, requieren la conformación de multi lóbulos.

La corteza, según Cahua y Sato (2012) fue de ecogenicidad de grano fino, moderadamente hipoecogénico, en tanto que en este estudio se observó una corteza de ecogenicidad y ecotextura granular media y homogénea. Ambos estudios coinciden que la médula se observa anecoica, con bordes hiperecogénicos, y la pelvis se observa como un tejido hiperecogénico en donde confluyen los lóbulos. En cuanto a las dimensiones del riñón, Cahua y Sato (2012) reportaron una longitud de $8.52 \mathrm{~cm}$ y un ancho de $3.24 \mathrm{~cm}$, valores dentro de los rangos encontrados en este estudio.

La topografía anatómica del bazo difiere de la descrita por Cahua y Sato (2012), pero es similar a lo descrito para el perro por Matton y Nyland (2016). Por otro lado, el órgano presentó un parénquima homogéneo granular fino, al igual que el perro (Matton y Nyland, 2016; Penninck y D'Anjou, 2008), en tanto que Cahua y Sato (2012) mencionan un parénquima homogéneo de grano grueso. $\mathrm{Al}$ igual que en el perro, los márgenes esplénicos fueron lisos y regulares, y el órgano presenta cabeza, cuerpo y cola (Matton y Nyland, 2016). Cahua y Sato (2012) reportaron un espesor de $2.24 \mathrm{~cm}$ (a nivel del hilio), dato que se encuentra dentro del rango determinado en este estudio. 
La vejiga se ubicó en la región pélvica, como se presenta en perro y otras especies domésticas (Matton y Nyland, 2016). Tiene un margen interno continuo, ligeramente ondulante en algunos casos, lo cual puede variar al igual que la forma según la cantidad de orina (Matton y Nyland, 2016). El grosor de la mucosa también varió dependiendo del contenido, siendo esta más gruesa a menor contenido. En perros, el grosor normal de la pared vesical varía entre 0.13 a $0.17 \mathrm{~cm}$ (Penninck y D'Anjou, 2008), mientras que, en este estudio, tanto para machos como hembras, la media fue mucho mayor. La pared se observó ecogénica, similar al perro; sin embargo, las capas que la conforman fueron poco definidas, como se ha descrito en el perro y otras especies domésticas (Penninck y D'Anjou, 2008, Matton y Nyland, 2016), con contenido anecoico.

Los testículos del oso de anteojos se ubicaron en las bolsas escrotales, con características similares a las descritas en el perro y otras especies domésticas (Matton y Nyland, 2016); sin embargo, a diferencia de estas especies, los osos de anteojos presentaron un mediastinum testis poco remarcado $\mathrm{y}$ algo discontinuo.

Finalmente, no se pudo distinguir ninguna de las secciones del aparato reproductor en los tres individuos hembra. Esta situación se presenta frecuentemente en la perra, que bajo condiciones normales no se suelen identificar los ovarios ni los cuernos uterinos en etapa de anestro, debido a su pequeño tamaño, además de la dificultad que genera el gas de las asas intestinales y el tejido adiposo que los rodea (Penninck y D'Anjou, 2015; Matton y Nyland, 2016).

\section{Agradecimientos}

Los autores agradecen al Patronato del Parque de las Leyendas «Felipe Benavides Barreda», por las facilidades brindadas en la realización del presente estudio, y a la empresa Ultrason Vet EIRL por facilitar el equipo ecográfico empleado.

\section{Literatura Citada}

1. Barr ED, Pinchbeck, GL, Clegg PD, Singer ER. 2006. Accuracy of diagnostic techniques used in investigation of stifle lameness in horses - 40 cases. Equine Vet Educ 18: 326-331. doi: 10.1111/j.2042-3292.2006.-tb00471.x

2. Bechshoft T, Jakobsen J, Sonne, C, Dietz R. 2011. Distribution of vitamins A (retinol) and E (á-tocopherol) in polar bear kidney: implications for biomarker studies. Sci Total Environ 409: 3508-3511. doi: 10.1016/j.scitotenv.2011.05.036

3. Cahua UJ, Sato SA. 2012. Reporte ultrasonográfico postmortem de órganos abdominales del oso de anteojos (Tremarctos ornatus). Rev Inv Vet Perú 23: 235-239. doi: 10.15381/rivep.v23i2.904

4. Carvalho FS, Bagetti HJ, Henry R, Pereira-Sampaio MA. 2009. The bovine kidney as an experimental model in urology: external gross anatomy. Cells Tissues Organs 190: 53-58.

5. Castellanos A, Arias L, Payan E, RuizGarcía M. 2010. Hematology and blood chemistry of the Andean bear (Tremarctos ornatus) in Ecuador. Ursus 21: 115-120.

6. Chávez AM. 2018. Influencia del hábitat y la estacionalidad sobre la dieta del oso andino (Tremarctos ornatus) en el distrito de Corosha, departamento de Amazonas. Tesis de Biólogo. Lima, Perú: Univ. Peruana Cayetano Heredia. 120 p.

7. [CITES] Convención sobre el Comercio Internacional de Especies Amenazadas de Fauna y Flora Silvestres. 2017. Apéndices I, II y III. [Internet]. Disponible en: https://cites.org/esp/app/ appendices.php

8. Cubas ZS, Silva JCR, Catão-Dias JL. 2014. Tratado de animais selvagens. $2^{\circ}$ ed. Sao Paulo: Ed. Roca. 2512 p.

9. Done SH, Goody PC, Stickland NC, Evans $S A .2010$. Atlas en color de anatomía veterinaria: el perro y el gato. $2^{\circ}$ ed. Barcelona: Elsevier. 544 p. 
10. Evans HE, deLahunta A. 1991. Disección del perro de Miller. Pennsylvania, USA: Interamericana Mac GrawHill. $368 \mathrm{p}$.

11. Fowler E, Miller E. 2015. Fowler's zoo and wild animal medicine. Vol 8. Elsevier. $773 \mathrm{p}$.

12. Goocicka D, Tomasik E. 1979. Extent of vascularization by the two branches of the renal artery in the brown bear (Ursus Arctos). Anat Embryol 157: 227229. doi: 10.1007/BF00305162

13. Gonzales FN, Neira-Llerena $J$, Llerena G, Zeballos H. 2016. Small vertebrates in the spectacled bear's diet (Tremarctos ornatus Cuvier, 1825) in the north of Peru. Rev Peru Biol 23: 61-66. doi: 10.15381/rpb.v23i1.11834

14. Langer P. 2018. Comparative Anatomy of the gastrointestinal tract in Eutheria: taxonomy, biogeography and food. Vol 2: Laurasiatheria, general discussion. Germany: De Gruyter. 380 p.

15. Matton JS, Nyland TG. 2016. Diagnóstico ecográfico en pequeños animales. $3^{\circ}$ ed. Barcelona: Multimédica. $756 \mathrm{p}$.

16. MINAGRI - SERFOR. 2016. Plan Nacional de Conservación del Oso Andino (Tremarctos ornatus) en el Perú. Periodo 2016 - 2026. Lima. [Internet]. Disponible en: http://siar.minam.gob.pe/ puno/documentos/plan-nacionalconservacion-oso-andino-tremarctosornatus

17. Penninck D, D'Anjou MA. 2008. Atlas de ecografía en pequeños animales. Barcelona: Multimédica. $520 \mathrm{p}$.
18. Penninck, D, D'Anjou MA. 2015. Atlas de ecografía en pequeños animales. $2^{\circ}$ ed. Barcelona: Multimédica. $553 \mathrm{p}$.

19. Raven H. 1936. Notes on the anatomy of the viscera of the giant panda (Ailuropoda melanoleuca). American Museum Novitates 877: 23 p. [Internet]. Disponible en: https://digitallibrary.amnh.org/handle/2246/4136

20. Stenvinkel P, Painer J, Kuro-O M, Lanaspa M, Arnold W, Ruf, T, Shiels PG Johnson RJ. 2018. Novel treatment strategies for chronic kidney disease: insights from the animal kingdom. Nat Rev Nephrol 14: 265-284. doi: 10.1038/ nrneph.2017.169

21. Velez-Liendo X, García-Rangel S. 2017. Tremarctos ornatus (version errata publicada en 2018). The IUCN Red List of Threatened Species 2017: e.T22066A123792952. [Internet]. Disponible en: https://dx.doi.org/10.2305/ IUCN.UK.2017-3.RLTS.T22066A45034047.en

22. Wallace R, Reinaga A, Siles T, Baiker J, Goldstein I, Ríos-Uzeda B, et al. 2014. Andean bear priority conservation inits in Bolivia \& Peru. Bolivia: Wildlife Conservation. $80 \mathrm{p}$.

23. Yerena E, Monsalve Dam D, Torres $D A$, Sánchez A, García-Rangel $S$, Bracho AE, Martínez Z, Gómez I. 2007. Plan de acción para la conservación del oso andino (Tremarctos ornatus) en Venezuela (2006-2016). Venezuela: Fundación AndígenA, FUDENA. $60 \mathrm{p}$. 